\title{
Experimental Maedi Visna Virus Infection in sheep: a morphological, immunohistochemical and PCR study after three years of infection
}

\author{
S. Preziuso, ${ }^{*}$ E. Taccini, ${ }^{*}$ G. Rossi, ${ }^{\circ}$ G. Renzoni, ${ }^{\circ}$ G. Braca* \\ * Dipartimento di Patologia Animale, Facoltà di Medicina Veterinaria, Università di Pisa, Italy; \\ 'Dipartimento di Scienze Veterinarie, Facoltà di Medicina Veterinaria, Università di Camerino, Italy
}

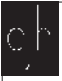

(C)2003, European Journal of Histochemistry

A morphological, immunohistochemical and polymerase chain reaction (PCR) study was performed on eight ewes experimentally infected with an Italian strain of Maedi-Visna Virus (MVV) in order to evaluate the lesions and the viral distribution after three years of infection. At the moment of euthanasia, seven sheep were seropositive for MVV, while one sheep in poor body conditions was seronegative since one year. Lungs, pulmonary lymph nodes, udder, supramammary lymph nodes, carpal joints, the CNS, spleen and bone marrow of the eight infected sheep were collected for histology, for immunohistochemical detection of the MVV core protein p28 and for PCR amplification of a 218 bp viral DNA sequence of the pol region. The most common histological findings consisted of interstitial lymphoproliferative pneumonia and lymphoproliferative mastitis of different severity, while no lesions were observed in the CNS. MVV p28 antigen was immunohistochemically labelled in lungs, udder, pulmonary lymph nodes, spleen and bone marrow but not in the CNS of all the eight infected sheep. A $218 \mathrm{bp}$ sequence of MVV pol region was detected in lung of a seropositive and of the seroconverted negative sheep. The results suggest that (i) MVV causes heterogeneous lesions in homogeneously reared ewes, (ii) MVV p28 antigen is detectable not only in inflammed target organs, but also in pulmonary lymph nodes, spleen and bone marrow, and (iii) immunohistochemistry and PCR are useful methods for Maedi-Visna diagnosis in suspected cases, also when serological tests are negative.

Key words: sheep, Maedi-Visna virus, experimental infection, histopathology, immunohistochemistry, PCR.

Correspondence: Dott.ssa Silvia Preziuso, Dipartimento di Patologia Animale, Facoltà di Medicina Veterinaria, Università di Pisa, v.le delle Piagge 2, 56124 Pisa, Italy.

Phone: international +39.050 .570737 . Fax. international +39.050.540644. E-mail: sprezius@vet.unipi.it

Paper accepted on June 23, 2003

European Journal of Histochemistry 2003; vol. 47 issue 4 [0ct-Dec]: 373-378
$\mathrm{M}$ aedi-Visna (MV) is a chronic, progressive and incurable disease of sheep discovered by Sigurdsson et al. $(1952,1957)$ in Iceland and described throughout the world with the exception of Australia and New Zealand (Brodie et al., 1998). The etiologic agent Maedi Visna Virus (MVV) is a lentivirus in the family Retroviridae that is closely related to caprine arthritis-encephalitis virus (CAEV) of goat.

The disease is characterized by a long incubation period (months or years), a progressive lymphoproliferative inflammation, and a slow development of disease symptoms (Pepin et al., 1998). The main target organs reported are lungs (maedi) (Sigurdsson et al., 1952) and the central nervous system (visna) (Sigurdsson et al., 1957), but udder and joints may also be affected (Cutlip et al., 1985a and 1985b). The virus infects cells of the monocyte/macrophage lineage, although viral DNA and RNA have been identified also in other cell types (Brodie et al., 1995; Vitali et al., 1997; Ryan et al., 2000). The major manifestations of the progressive inflammation induced by MVV are chronic weight loss, primary interstitial pneumonia, encephalitis, mastitis, arthritis, and lymphadenophathy (Brodie et al., 1998).

The high genomic variability of the virus has contributed to originate several viral strains with different pathogenicity and organ tropism (de la ConchaBermejillo, 1997); for this reason, the clinical and pathological manifestations of MVV infection in different geographic areas can be variable. In Italy, where ovine milk is important for the production of several typical cheeses and for lambs feeding, MVV causes relevant economic losses, mainly due to the indurative mastitis and the consequent lower milk production. The main target organs of Italian strains of MVV seems to be lungs and udder, while the central nervous system and joints are rarely affected (Gelmetti et al., 1998).

The aim of this study is to evaluate the clinical and 
pathological changes and the viral distribution in a group of ewes experimentally infected with an Italian field isolate of MVV and killed about three years after inoculation.

\section{Materials and Methods}

\section{Experimental animals}

A flock of ten Sardinian ewes born from uninfected sheep was maintained in a common isolation pan and their seronegativity for MVV was checked for 8 months by AGIDT and ELISA (Saman et al., 1999). Eight of the ten seronegative ewes (\#1-8) were intratracheally infected with the Italian field isolate strain 130 of MVV (Rosati et al., 1992), while two animals (\#9 and 10) were kept as uninfected control. At regular intervals, serum samples were tested by specific AGIDT and ELISA (Saman et al., 1999) in order to monitor the positive seroconversion.

\section{Sampling procedures}

Euthanasia of the sheep was performed about three years after inoculation. At necropsy, 4-6 samples from different sites of lungs, pulmonary lymph nodes, udder, supramammary lymph nodes, carpal joints, the CNS, spleen and bone marrow were fixed in buffered formalin for 24-48 hours and embedded in paraffin for histology and immunohistochemistry. Small samples of bone marrow were decalcified in $10 \%$ w/v EDTA-Na solution for 3 days before paraffin embedding. Samples of lungs were also frozen at $-80^{\circ} \mathrm{C}$ for DNA extraction. For virology, fresh samples of lungs, udder, spleen, choroid plexus and carpal synovial membrane of six animals (\#1, 2, 4, 5,6 , and 7) were submitted to the Laboratory of Virology of the Department of Animal Pathology (Pisa). Samples of lung, udder and joints were also submitted for pathogenic bacteria and mycoplasma isolation.

\section{Immunohistochemistry}

A 1:1000 dilution of a monoclonal antibody (MoAb) to the MVV core protein p28 (VMRD Inc, Pullman, WA, USA) was reacted with deparaffinized and rehydrated slides. A 1:1000 dilution of an ovine anti-macrophages antibody (MoAb VPM32; University of Edinburgh, UK) was also used on serial sections in order to phenotype the p28 positive cells. The procedures utilized an avidin-biotin-peroxidase complex $(A B C)$ technique (Vectastain Elite $A B C$ Kit; Vector Laboratories, Burlingame, CA,
USA) with diaminobenzidine as the chromogen (Peroxidase substrate kit-DAB; Vector Laboratories), following the manufacture instructions. In particular, the procedure used was: block for endogenous peroxidase in $3 \% \mathrm{H}_{2} \mathrm{O}_{2}$ at room temperature (RT) for 30 minutes, washing ( 3 times for 5 minutes each) in $10 \mathrm{mM}$ sodium phosphate $\mathrm{pH} 7.5$ (PBS), antigen unmasking in microwave oven at 650W for 10 minutes in $10 \mathrm{mM}$ citric acid buffer $\mathrm{pH}$ 6.0, washing in PBS, incubation with horse normal serum at RT for 30 minutes and then with the $\mathrm{MoAb}$ at $4^{\circ} \mathrm{C}$ for 15 hours, washing in PBS, incubation with horse normal serum at RT for 30 minutes, incubation with biotinylated universal antibody at RT for 45 minutes, washing in PBS, incubation with avidin-peroxidase conjugate at RT for 45 minutes, washing in PBS and incubation with DAB at RT for 5 minutes. After staining developing, a weak counterstain was carried out with Herris' haemathoxylin. For control purposes, tissues of uninfected sheep, omission of the primary antibody and irrelevant MoAb were used.

\section{Polymerase chain reaction}

DNA was extracted from frozen samples of sheep \#4 and 8 by phenol-chloroform technique. The polymerase chain reaction (PCR) primers were specific for a 218 bp segment of the pol region of MVV (sense: 5'ATAGTAAATGGCATCAAGATGC-3'; antisense: 5'TCCCGAATTTGTTTCTACCC-3'). Each PCR mixture (PCR core kit; Roche, Mannheim, Germany) contained $2 \mu \mathrm{g}$ DNA template, IX PCR buffer, $0.2 \mathrm{mM}$ dNTP, $1 \mu \mathrm{M}$ sense and antisense primers, $2.5 \mathrm{U}$ taq and $\mathrm{H}_{2} \mathrm{O}$ up to a final volume of $50 \mu \mathrm{L}$. The amplification process consisted of 1 cycle at $95^{\circ} \mathrm{C}$ for $5 \mathrm{~min}, 35$ cycles at $95^{\circ} \mathrm{C}$ for $1 \mathrm{~min}, 58^{\circ} \mathrm{C}$ for $1 \mathrm{~min}, 72^{\circ} \mathrm{C}$ for $1 \mathrm{~min}$, with final extension at $72^{\circ} \mathrm{C}$ for 2 min.

\section{Results}

\section{Clinical findings}

About two years after infection, sheep \#8 showed progressive weight loss and anaemia up to cachexia; a corresponding decrease of ELISA values up to a persistent seronegativity was observed. Ten months after negative seroconversion, the sheep was euthanized because the poor body conditions. The other ewes, excepted the \#5, showed only a progressive symmetrical indurative mastitis. 


\section{Gross findings}

At necropsy, the lungs of sheep \#4 and 8 failed to collapse and demonstrated small ( $1 \mathrm{~mm})$, diffused and scattered grey foci on pleural and cut surfaces in interstitial and perilobular design. On the pleural surfaces of sheep \#4 there were also three small (2$3 \mathrm{~mm}$ ), dark-reddish foci of pulmonary small strongyles incubation. The udder was firm in all the infected ewes excepted \#5, which was normal. The left carpal joint of sheep \#3 showed a slight increase of the synovial fluid.

The necropsy of sheep \#8 showed also the presence of some Cysticercus tenuicollis on thoracic and abdominal serous membranes, and parasitological investigations of the digerent tract revealed a severe Haemoncus sp. infection, probably responsible for the poor body conditions of the sheep.

The other organs examined did not revealed any gross modification.

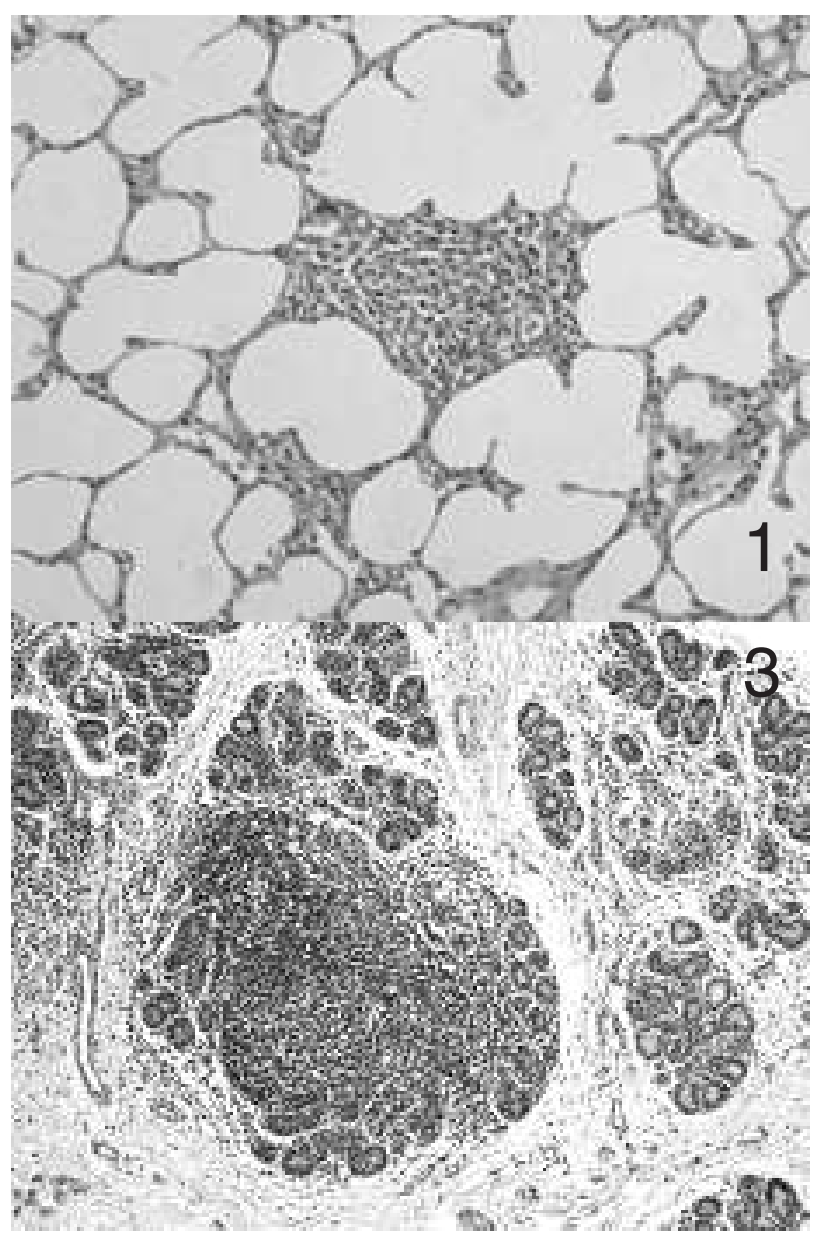

\section{Microscopic lesions}

Histological observation of the lung showed the presence of lesions of different severity in all the eight infected ewes (Table I). Sheep \# 1, 5, and 7 showed mild pulmonary lesions, consisting in small infiltrations of mononuclear cells mainly associated with vascular structures. Sheep \#2 and 3 had moderate lesions, with many mononuclear cells within alveolar septa, an higher number of bigger lymphoid aggregates (Figure 1) and BALT (Bronchus Associated Lymphoid Tissue) hyperplasia. Sheep \#4, 6, and 8 had severe pulmonary lesions, with many big lymphoid aggregates with germinal centers, loss of the normal alveolar structure, fibromuscolar proliferation and fibrosis (Figure 2).

Pulmonary lymph nodes appeared normal in sheep \#3 and 5, moderately hyperplastic in sheep \#2 and 7 and markedly hyperplastic in sheep \#4, 6, and 8 . Lymph nodes hyperplasia was characterized by

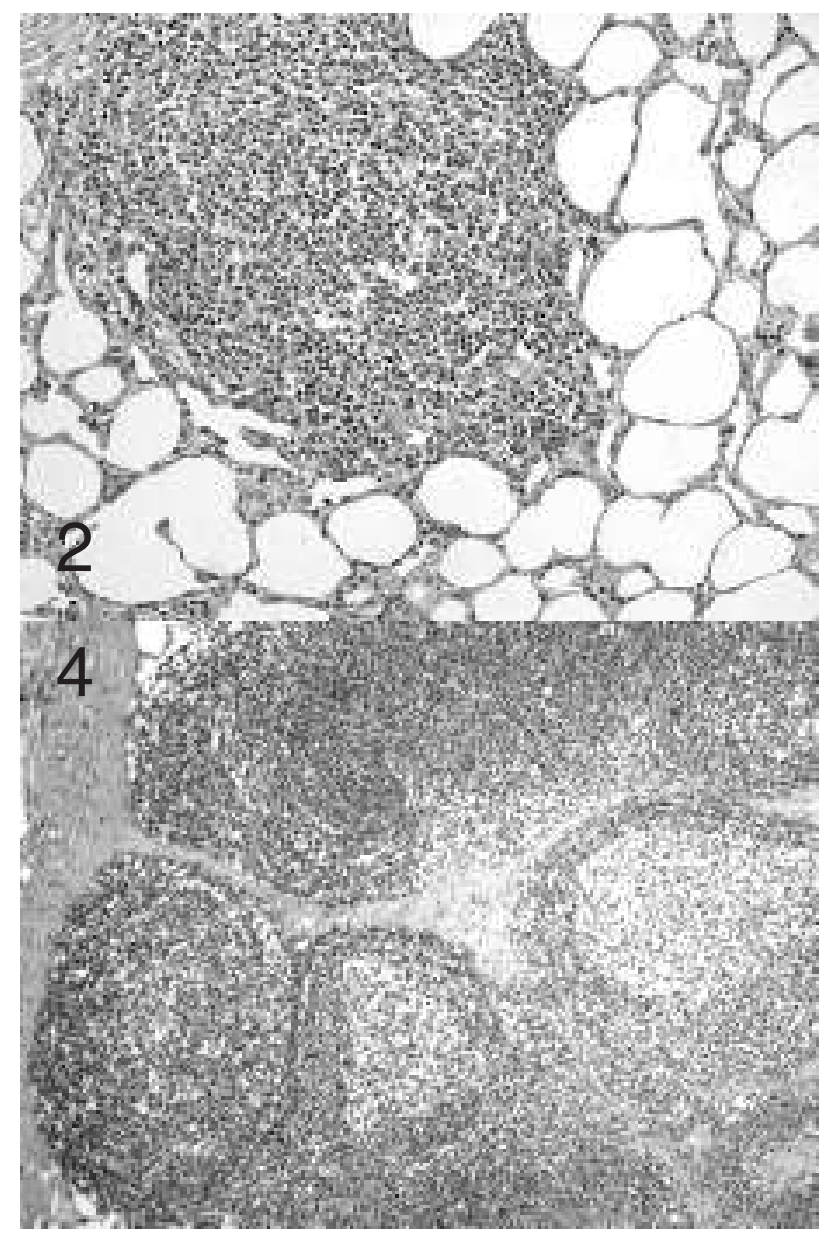

Figure 1. Lung of MVV infected ewe. Medium size lymphoid aggrgate. Light infiltration of mononuclear cells within alveolar septa. H.E. 20X. Figure 2: Lung of MVV infected ewe. Big lymphoid aggregate, with germinal center and numerous lymphoblasts. H.E. 20X. Figure 3. Udder of MVV infected ewe. Severe mononuclear infiltration diffuse in the interstitium and in follicular-like arrangement. H.E. 10X. Figure 4: Supramammary lymph nodes of MVV infected ewe. Lymphoid follicles in various states of activity, with numerous active secondary follicles. H.E. 10X. 
Table 1. Summary of the ELISA, virological, PCR and histological results.

\begin{tabular}{|c|c|c|c|c|c|c|c|c|c|c|c|c|}
\hline \multirow{3}{*}{$\begin{array}{l}\text { Sheep } \\
\text { No. }\end{array}$} & \multirow{3}{*}{$\begin{array}{c}\text { histology } \\
\text { No. }\end{array}$} & \multirow{3}{*}{$\begin{array}{c}\text { ELISA } \\
\text { at } \\
\text { euthanasia }\end{array}$} & \multirow[t]{3}{*}{ Virology } & \multirow[t]{3}{*}{$P C R$} & \multicolumn{8}{|c|}{ Histology } \\
\hline & & & & & \multicolumn{3}{|c|}{ lungs } & \multicolumn{3}{|c|}{ udder } & \multirow[t]{2}{*}{ Joints } & \multirow[t]{2}{*}{ CNS } \\
\hline & & & & & mild & moderate & severe & $\overline{\text { follicular }}$ & diffuse & mixed & & \\
\hline 1 & 7493 & + & + & & + & & & & + & & - & - \\
\hline 2 & 7419 & + & + & & & + & & & & + & - & - \\
\hline 3 & 7374 & + & & & & + & & & & + & + & - \\
\hline 4 & 7527 & + & + & + & & & + & + & & & + & - \\
\hline 5 & 7439 & + & + & & + & & & - & - & - & - & - \\
\hline 6 & 7563 & + & + & & & & + & & & + & - & - \\
\hline 7 & 7452 & + & + & & + & & & + & & & - & - \\
\hline 8 & 7129 & - & & + & & & + & & + & & - & - \\
\hline
\end{tabular}

expansion of the cortex with numerous lymphoid follicles in various states of activity. Active secondary follicles, with well defined germinal centers, were particularly numerous in sheep \#2, 4, and 6. All the hyperplastic lymph nodes had medullary cords moderately to markedly widened.

In the udders, seven of the eight infected animals showed three different kinds of lesions, while sheep \#5 did not show any alteration (Table 1). In particular, sheep \#1 and 8 had diffuse accumulation of mononuclear cells in the glandular interstitium, sheep \#4 and 7 had dense infiltrates of mononuclear cells with periductal lymphoid nodules containing germinal centers, and sheep \#2, 3, and 6 had severe mononuclear infiltration and lymphoid proliferation diffuse in the interstitium and forming nodules not ever associated to ductal structures (Figure 3 ).

Supramammary lymph nodes hyperplasia was detected only in sheep \#7 (moderate) and \#2 (severe), while in the other samples the cortex and the medullary cords were not expanded. Several active secondary follicles were detected in sheep \# 1 , $2,4,6,7$, and 8 (Figure 4).

In carpal joints of sheep \#3 and slighter of sheep \#4 was present diffuse infiltration of mononuclear cells, mainly lymphocytes, sometimes with perivascular arrangement.

No histological changes were found in sections of brain and spinal cord.

\section{Immunohistochemistry}

A cytoplasmatic immunostaining was detected in cells of lungs, pulmonary lymph nodes, udders, spleen and bone marrow of all the eight infected ewes, independently of the severity of the organ lesions. In the lungs, the labelled cells were mainly located within alveolar septa and in mononuclear aggregates (Figure 5); in the small nodular aggre- gates the positive cells were mixed with the infiltrating cells, while in the bigger nodules they were located mainly at the periphery. A strong labelling was observed in many mononuclear cells surrounding the parasites foci in lungs of sheep \#4 (Figure 6). In the pulmonary lymph nodes, MVV antigen was detected in the subcapsular sinus and in the cortex, not only in macrophages but also in cells morphologically resembling dendritic cells (Figure 7 ). In the udder, p28 was present in the cytoplasm of macrophages in interlobular and intralobular connective tissue but not in periductal nodules (Figure 8). In the spleen, MVV positive cells were detected in the periphery but not in the center of the splenic follicles (Figure 9). MVV antigen was also detected in the cytoplasm of big, round to oval cells in bone marrow (Figure 10 ). None staining was obtained in brain and spinal cord samples.

The macrophagic origin of the round/oval positive cells in the tested organs was confirmed in serial sections by the immunolabelling with the MoAb VPM32.

\section{Polymerase chain reaction}

PCR performed on lung samples of the converted seronegative sheep (\#8) and of a seropositive and severely affected sheep (\#4) gave a product of the expected size (218 bp).

\section{Virology and microbiology}

MVV was isolated by samples of sheep $\# 1,2,4,5$, 6 , and 7; fresh samples of sheep \#3 and 8 were available for virology. No pathogenic bacteria and mycoplasma were isolated.

\section{Discussion}

MVV lesions observed after three years of experimental infection confirm that the Italian field strain 

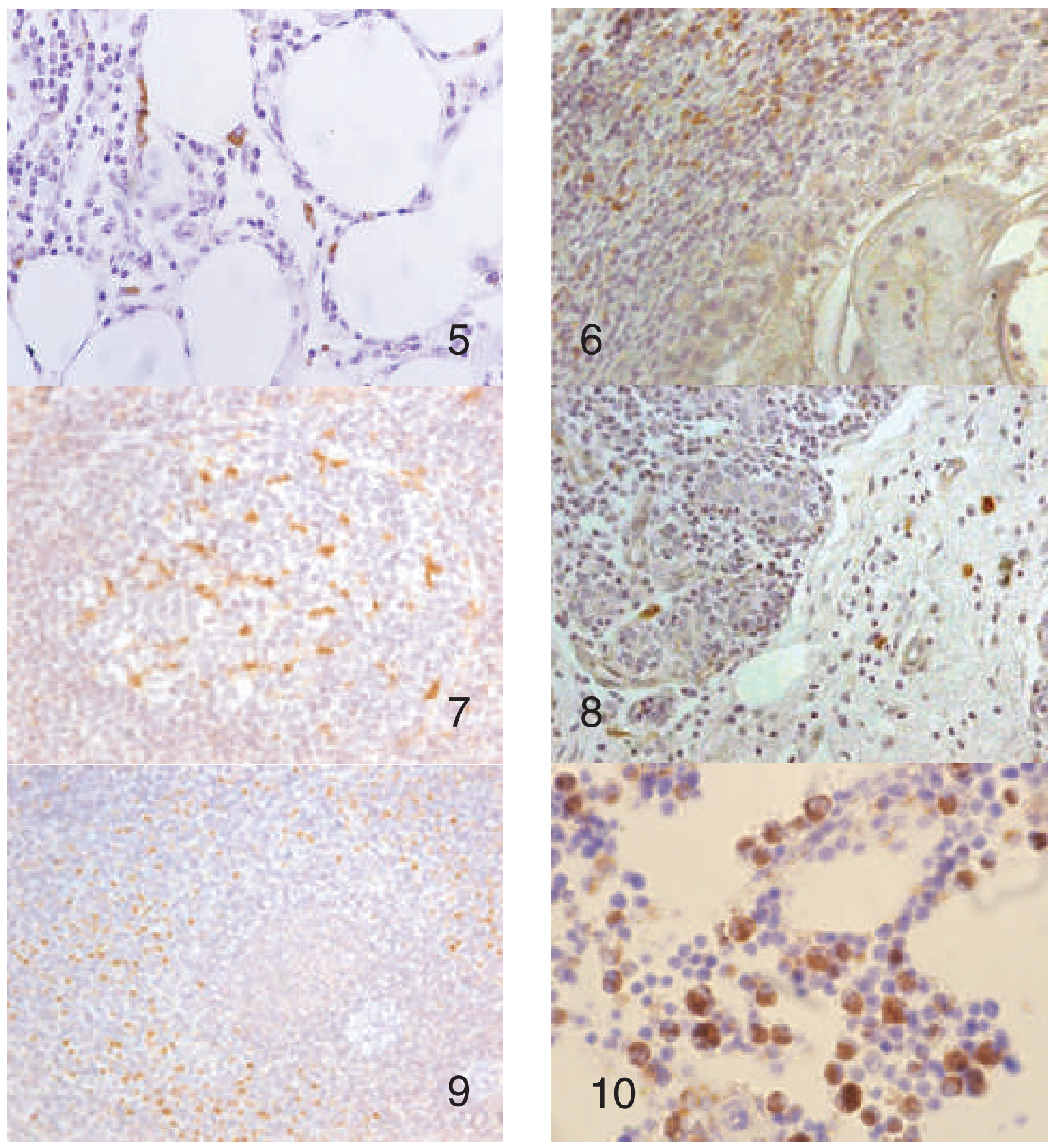

Figure 5. Lung of MVV infected ewe. Immunohistochemistry for MVV p28. Strong immunoreaction in the cytoplasm of cells within alveolar septa and small mononuclear aggregates. Haematoxilin counterstain. 40X. Figure 6. Lung of MVV infected ewe. Immunohistochemistry for MVV p28. Strong labelling in numerous mononuclear cells surrounding a small strongyle. Haematoxilin counterstain. 32X. Figure 7. Pulmonary lymph node of MVV infected ewe. Immunohistochemistry for MVV p28. Cytoplasmatic staining in mononuclear cells located in the center of a follicle and morphologically reseambling dendritic cells. Hematoxilin counterstain. $40 \mathrm{X}$. Figure 8. Udder of MVV infected ewe. Immunohistochemistry for MVV p28. Positive macrophages in interlobular and intralobular connective tissue. Haematoxilin counterstain. 32X. Figure 9. Spleen of MVV infected ewe. Immunohistochemistry for MVV p28. Positive mononuclear cells in the peripheral areas of splenic follicles. Haematoxilin counterstain. 20X. Figure 10. Bone marrow of MVV infected ewe. Immunohistochemistry for MVV p28. Strong immunolabelling in the cytoplasm of big, round to oval cells. Haematoxilin counterstain. 48X 
inoculated has a major tropism for lung and udder, where lesions of different severity were detected, while the CNS resulted not involved. The heterogeneity of the severity of the lesions observed in the organs of the eight infected sheep is probably related to individual genetic differences, because the ewes were homogeneously reared and no other causes of heterogeneity were found.

The immunohistochemical results observed show that viral antigen is detectable not only in inflammed target organs, but also in lymph nodes, spleen and bone marrow. The role of these latter tissues in MVV infection is not clear, but it is possible they are reservoir of the virus, as described in human immunodeficiency virus (HIV) infection (Blacklaws, 1997). The ability of MVV to infect macrophages is well known and recently it has been described MVV infection and replication also in dendritic cells (Rayan et al, 2000). The immunopositivity observed in our study in both macrophages and cells morphologically referable to dendritic cells suggests an involvement of these cells not only in the early stage of MaediVisna infection but still some years later.

In the lungs of sheep \#4, the presence of an intense immunolabelling in mononuclear cells located around parasite foci could be explained as follows. MVV infects monocytes, which participate numerous in inflammatory processes as macrophages. During the transformation of monocytes to macrophages, the genome expression of MVV increases, as demonstrated by Gendelman et al. (1996). It is thus possible that concurrent inflammations increase MVV expression, as recently found in epididymis of rams affected by Brucella ovis and MVV infection (Preziuso S et al., 2003).

Finally, immunohistochemical and PCR detection of MVV in sheep \#8, seronegative at the moment of necropsy, demonstrates these techniques as diagnostic tools. In particular, IHC for MVV is recommended for differential diagnosis when lymphoid infiltrates are observed in target organs, also when serological tests are negative.

\section{Acknowledgments}

Prof. Ennio Sanna, University of Sassari (Italy), for his help in PCR protocol. Prof. Francesco Tolari and Prof. Patrizia Bandecchi, University of Pisa (Italy), for serological results and for MVV isolation.

\section{References}

1. Blacklaws BA. Quantification of the reservoir of HIV-1. Trends Microbiol 1997; 5:215-6.

2. Brodie SJ, Pearson LD, Zink MC, Bickle HM, Anderson BC, Marcom KA, et al. Ovine lentivirus expression and disease. Virus replication, but not entry, is restricted to macrophages of specific tissues. Am J Pathol 1995; 146:250-63.

3. Brodie SJ, de la Concha-Bermejillo A, Snowder GD, DeMartini JC. Current concepts in the epizootiology, diagnosis, and economic importance of ovine progressive pneumonia in North America: a review. Small Ruminant Res 1998; 27:1-17.

4. Cutlip RC, Lehmkuhl HD, Brogden KA, Bolin SR. Mastitis associated with ovine progressive pneumonia virus infection in sheep. Am $J$ Vet Res 1985a; 46:326-8.

5. Cutlip RC, Lehmkuhl HD, Wood RL, Brogden KA. Arthritis associated with ovine progressive pneumonia. Am J Vet Res 1985b; 46:65-8.

6. de la Concha-Bermejillo A. Maedi-Visna and ovine progressive pneumonia. Vet Clin North Am Food Anim Pract 1997;13:13-33.

7. Ellis JA, DeMartini JC. Immunomorphologic and morphometric changes in pulmonary lymph nodes of sheep with progressive pneumonia. Vet Pathol 1985; 22:32-41.

8. Gelmetti D, Gibelli L, Matteucci F, Vecchi G, Cammarata G. Controllo delle patologie neurologiche degli ovini in Emilia Romagna. Selezione Veterinaria 1998;3:153-65.

9. Gendelman HE, Narayan O, Kennedy-Stoskopf S, Kennedy PGE, Ghotbi Z, Clements JE, et al. Tropism of sheep lentiviruses for monocytes: susceptibility to infection and virus gene expression increase during maturation of monocytes to macrophages. J Virol 1986; 58: 67-74.

10. Pepin M, Vitu C, Russo P, Mornex JF, Peterhans E. Maedi-visna virus infection in sheep: a review. Vet Res 1998; 29:341-67.

11. Preziuso S, Sanna E, Sanna MP, Loddo C, Cerri D, Taccini E, et al. Association of Maedi Visna virus with Brucella ovis infection in rams. Eur J Histochem 2003; 47:151-8.

12. Rayan S, Tiley L, McConnell I, Blacklaws B. Infection of dendritic cells by the Maedi-Visna lentivirus. J Virol 2000; 74:10096-103.

13. Rosati S, Tolari F, Bollo E. Identification of lentiviruses isolated from outbreaks of ovine maedi and caprine arthritis encephalitis. Proc Ann Meet Ital Soc Vet Sci 1992; 46:883-6.

14. Saman E, van Eynde G, Lujan L, Extramiana B, Harkiss G, Tolari $F$, et al. A new sensitive serological assay for detection of lentivirus infections in small ruminants. Clin Diagn Lab Immun 1999; 6:73440.

15. Sigurdsson B, Grimsson H, Palsson PA. Maedi: A chronic progressive infection of sheep lungs. J Infect Dis 1952; 90:233-241.

16. Sigurdsson B, Palsson PA, Grimsson H. Visna, a demyelinating transmissible disease of sheep. J Neuropathol Exp Neurol 1957; 16:389-403.

17. Spira AI, Marx PA, Patterson BK, Mahoney J, Koup RA, Wolinsky SM, Ho DD. Cellular targets of infection and route of viral dissemination after an intravaginal inoculation of simian immunodeficiency virus into rhesus macaques. J Exp Med 1995; 183:215-25.

18. Vitali CG, Sanna E, Braca G, Boero L, Rossi G, Leoni A. In situ techniques for the detection of proviral DNA in sheep mastitis caused by MVV (Conference abstract). In: JJ Badiola ed. Proceedings of the Third European Workshop on Ovine and Caprine Retroviruses, Jaca (Spain), 1997, p. 23. 